\title{
Low-frequency earthquakes along the Ryukyu Islands triggered by teleseismic earthquakes
}

\author{
Ayumi Kinjo and Mamoru Nakamura ${ }^{*}$ (])
}

\begin{abstract}
Tremors and low-frequency earthquakes (LFEs), which occur in the plate interface, can provide useful information about the state of aseismic stress transfer in mega-earthquake fault zones. We estimated the distribution of triggered LFEs in the subducted plate interface. Specifically, we detected LFEs in the Ryukyu Trench triggered by the surface waves of large teleseismic earthquakes by using the waveform records of broadband and short-period seismometers installed in the Ryukyu Arc. We selected a total of 45 teleseismic earthquakes with magnitudes of more than 7.5, which occurred between 2004 and 2017, for the analysis. We could detect the triggered LFEs for five teleseismic earthquakes. Then, we determined the hypocenters of LFEs by using the relative arrival times of LFEs for each station. The LFEs were distributed in the south of Okinawa Island and the Yaeyama area. Moreover, they were distributed around the source fault of the slow slip events. These were almost the same as and concentrated near to the locations of the most active LFE clusters accompanying very low-frequency earthquakes, suggesting higher sensitivity of inducing LFEs near these clusters. This indicates that the LFEs accompanying VLFEs are activated by stress acceleration in the Yaeyama and Okinawa areas.
\end{abstract}

Keywords: Low-frequency earthquake, Surface wave, Slow earthquake, Ryukyu trench

\section{Introduction}

The activity of non-volcanic tremors, which are one type of slow earthquake, in the plate interface can provide useful information about the movement of aseismic slip in mega-thrust fault zones, and such data can be indicative of the heterogeneity of stress sensitivity and aseismic stress accumulation in the plate interface (Obara and Kato 2016). These tremors have different characteristics to those of regular earthquakes such as a long-duration, emergent onset, and lack of high-frequency components of wave energy. The tremors have been observed in various areas around the circum-Pacific plate boundaries (Obara 2002; Rogers and Dragert 2003; Nadeau and Dolenc 2005; Payero et al. 2008; Fry et al. 2011; Obara and Kato 2016). Before 2009, tremors that occurred in

${ }^{*}$ Correspondence: mnaka@sci.u-ryukyu.ac.jp

University of the Ryukyus, Okinawa 9030213, Japan the down-dip extension of the seismogenic zone had been observed, but later, those that occurred in the updip extension were detected (Obara and Kodaira 2009; Walter et al. 2011; Ito et al. 2015; Yamashita et al. 2015; Tanaka et al. 2019). The existence of these tremors and activity changes induced by external stress implies that aseismic slip proceeds in the up-dip and down-dip of the plate interface, and the tremor activity in the up-dip and down-dip of the plate interface is influenced by small stress perturbations in these areas.

We focused on triggered tremors (i.e., low-frequency earthquakes or LFEs) caused by dynamic stress changes to estimate the distribution of stress sensitivity in the plate interface within the Ryukyu subduction zone. Although tremors usually have occurred as ambient tremors, those triggered by the surface waves of teleseismic earthquakes also have been observed (Miyazawa and Mori 2006; Rubinstein et al. 2007; Peng et al. 2008; 
Gomberg et al. 2008; Chao et al. 2012a, b, 2013). The characteristics of the triggered tremors are similar to those of the ambient tremors, and so is their mechanism. Therefore, the detection of triggered tremors can implicate the existence of ambient tremors (Gomberg 2010; Fry et al. 2011; Ide 2012; Chao et al. 2013; Sun et al. 2015).

Tremors triggered by the surface waves of large earthquakes also have been observed in the Ryukyu Trench. Chao and Obara (2016) reported that a tremor (LFE) was detected in the high-frequency component of a broadband seismometer when the surface waves of a M8-class teleseismic earthquake passed over the Yaeyama area, to the southwest of the Ryukyu Trench. Because the tremors were observed at stations IGK and YNG of the F-net, which were established by the National Research Institute for Earth Science and Disaster Resilience (NIED) (Fig. 1), in the Yaeyama area, tremors were also assumed to have occurred in the Ryukyu Trench. However, because the F-net observation network has only two stations (IGK and YNG) in the Yaeyama area, it is a difficult task to determine the detailed hypocenter distribution of the tremors.

In this study, we detected the triggered LFEs, determined their hypocenters, and estimated the distribution of stress sensitivity in the Ryukyu subduction zone. We used the waveforms of the short-period seismic network operated by the Japan Meteorological Agency (JMA). This observation network of the short-period seismographs with a natural period of $1 \mathrm{~s}$ is distributed in the Ryukyu Islands. Because these seismographs are installed on the ground, the noise level of the waveforms is higher than that of borehole-type seismographs. Although these seismographs are not suitable for detecting weak signals, LFEs can be detected by this seismic network in some cases. Nakamura (2017) detected and located VLFE-LFEs from the waveforms of the JMA's short-period seismic network. The LFEs were clustered to the south of the Hateruma and Ishigaki islands, the area south of Okinawa Island, and the area northeast of Okinawa Island. If the LFEs occurred on the plate interface, their depths corresponded to $15-20 \mathrm{~km}$. According to the OBS survey conducted in the south of the Yaeyama area, the LFEs occurred on the subducting plate interface (Arai et al. 2016). The difference of distribution of the ambient and triggered LFEs can inform us about the lateral heterogeneity of stress sensitivity in the subducted plate interface.

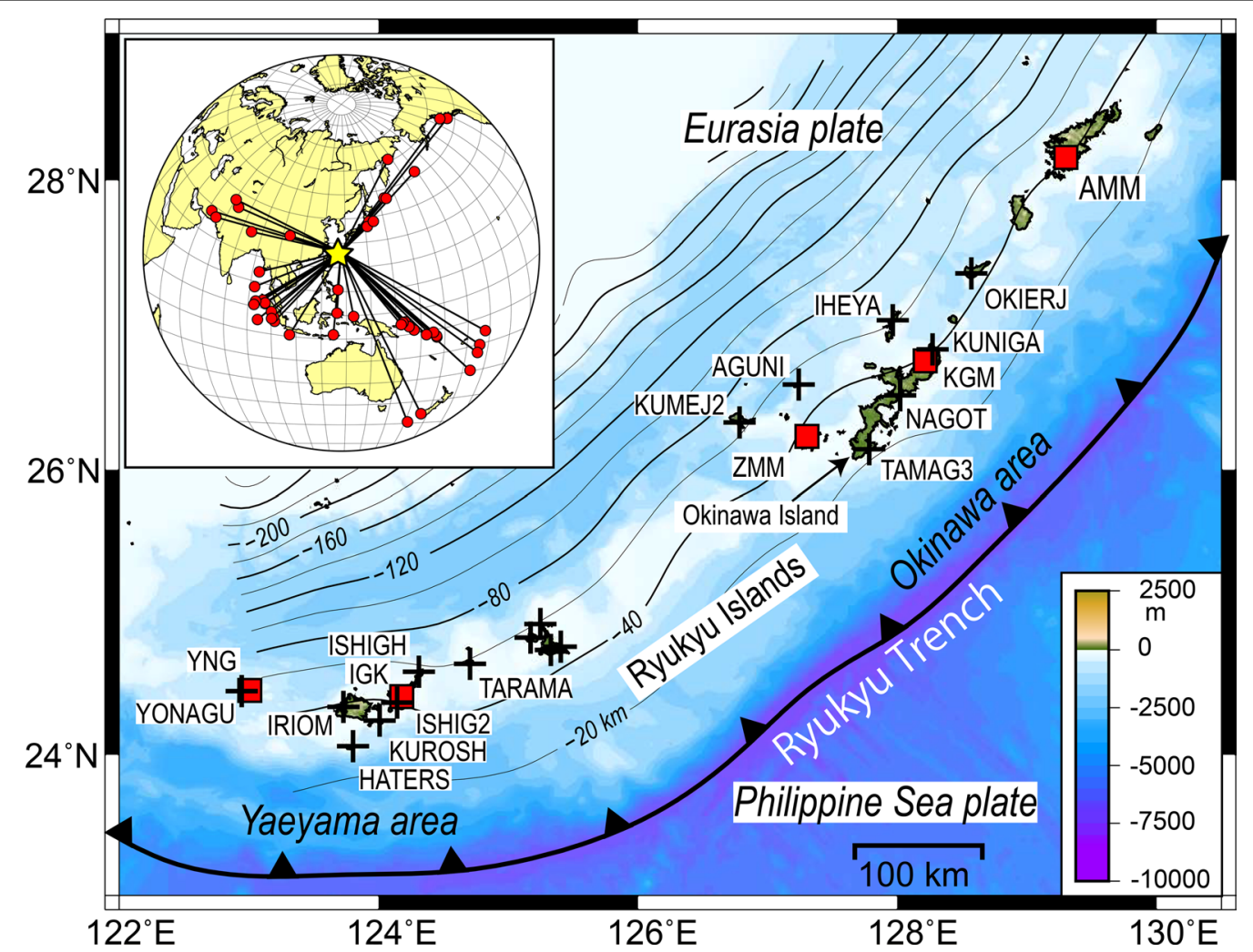

Fig. 1 Distribution of the seismic stations. Squares denote the F-net stations, and the crosses denote the JMA stations. Solid black contours show the depth of the plate interface (Hayers et al. 2012). The inset shows the distribution of the teleseismic earthquakes (red circles) used in this study 


\section{Data and methods \\ Data}

Earthquakes that occurred between January 2004 and December 2017 with magnitudes of more than 7.5, epicentral distances ranging from 15 to 90 degrees from Okinawa Island, and depths shallower than $300 \mathrm{~km}$ were used in the analysis (a total of 45 events) (Fig. 1, Additional file 1: Table S1). Broadband waveforms at IGK and ZMM of the F-net observation network were used. The instrumental responses of the waveforms were corrected. The short-period seismic waveforms of the JMA, $3 \mathrm{~h}$ from the occurrence of the earthquake, were also used to detect the LFEs.

\section{Detection of LFEs}

The waveforms of the broadband seismometers were 0.02-0.05 Hz bandpass-filtered to display the surface waves. The horizontal component waveforms of the short-period seismometer and F-net seismometers were $2-4 \mathrm{~Hz}$ bandpass-filtered to detect the LFEs. In general, the LFEs are analyzed in the frequency band of $2-8 \mathrm{~Hz}$ (Chao and Obara, 2016). However, the noise level of seismographs placed on the ground surface in this region is high, above $4 \mathrm{~Hz}$, which masks the LFE signal. Additional file 3: Figure S1 shows the waveforms at Yaeyama during the 2004 Sumatra earthquake. In the 2-4 Hz bandpassfiltered waveforms, the LFEs were observed at four stations (Additional file 3: Figure S1a). However, for the 4-8 Hz bandpass-filtered waveform, ISHIG2 failed to detect LFEs, and the correlation of the envelope waveforms between HATERS and KUROSH was poor (Additional file 3: Figure S1b). At $8-16 \mathrm{~Hz}$, the LFEs could not be detected at all stations (Additional file 3: Figure S1c). To determine the hypocenters of the LFEs, as many observation points as possible are needed. Therefore, we limited our LFE analysis to the frequency range of 2-4 Hz. Potential wave groups of the LFEs when the surface waves passed were visually selected from the shortperiod seismograms (Figs. 2, 3, Additional file 4: Figure S2, and Additional file 5: Figure S3).

\section{Hypocenter determination of LFEs}

To determine the hypocenters of the LFEs, the arrival time difference of the wave group of the LFEs among the stations was calculated by using the envelope correlation method (Obara 2002). We first applied a bandpass filter of $2-4 \mathrm{~Hz}$ to the short-period and broadband seismograms. We combined the horizontal component waveforms, and then, we calculated the RMS amplitudes every $1 \mathrm{~s}$ with a time-window of $10 \mathrm{~s}$. We calculated the cross-correlations of the RMS waveforms

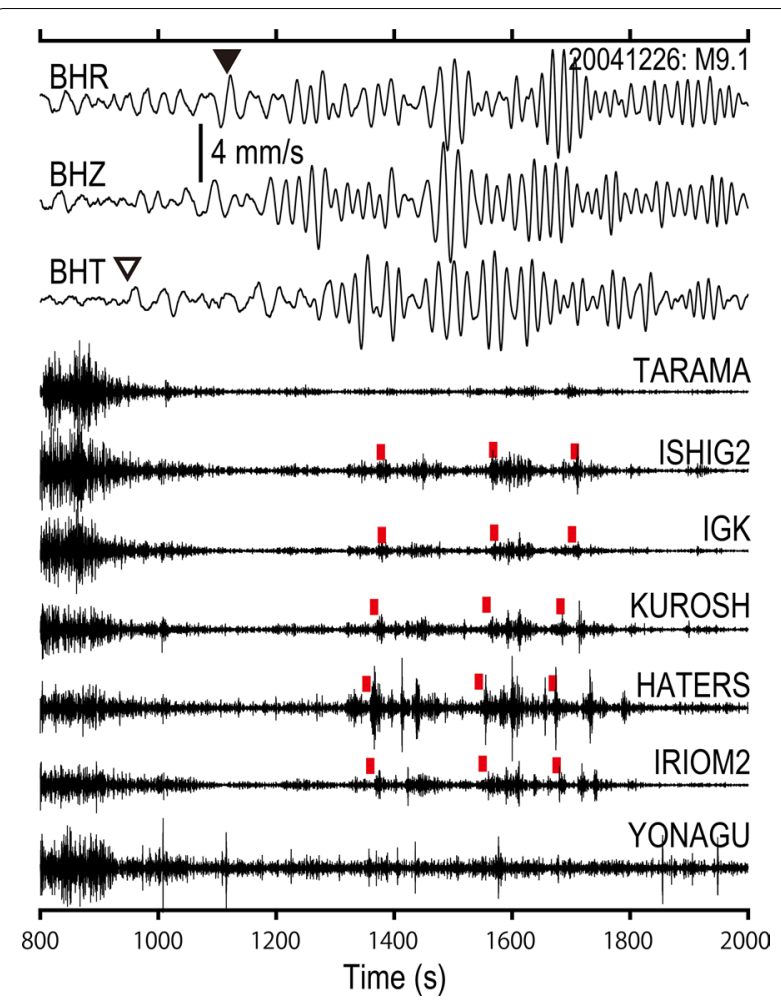

Fig. 2 Waveforms of the triggered LFEs observed in the Yaeyama area. Broadband and short-period seismographs of the 2004 Sumatra earthquake. Upper part shows the instrumentally corrected broadband seismograph at IGK. Zero time denotes the occurrence time of the earthquake. The black and white triangles denote the estimated arrival time of the Rayleigh and Love waves, respectively. The velocity of the Rayleigh and Love waves is assumed to be $4.0 \mathrm{~km} / \mathrm{s}$ and $3.4 \mathrm{~km} / \mathrm{s}$, respectively. The thick vertical bar shows the scale of the broadband seismograph. Lower part shows the $2-4 \mathrm{~Hz}$ bandpass-filtered short-period seismograph of the $\mathrm{N}-\mathrm{S}$ component. The triggered LFEs were recorded at several stations. The waveforms are plotted from western stations to eastern stations along the trench

between the two stations and examined the time lag between two waveforms when the cross-correlation was at its maximum, which is the arrival time difference between the two stations.

Next, we determined the hypocenters by using the grid-search method (Chao et al. 2013), which uses the observed and calculated arrival time difference among the stations. The arrival time difference when the crosscorrelation was over 0.7 was used for the hypocenter determination. As the waveforms of the LFEs were dominant with the $\mathrm{S}$-wave, the $\mathrm{S}$-wave velocity model was used in the grid-search method. The JMA2001 velocity model was used for the one-dimensional S-wave velocity structure (Ueno et al. 2002).

Finally, we compared the occurrence of LFE with the PGV in the Okinawa and Yaeyama areas. We chose the 


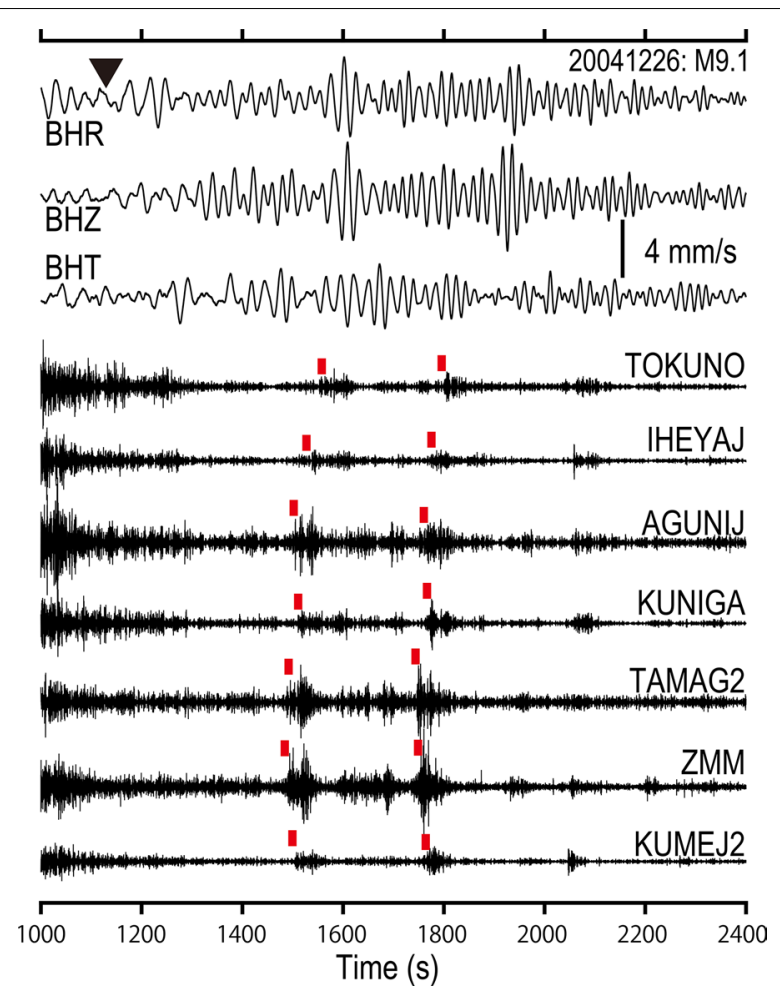

Fig. 3 Waveforms of the triggered LFEs observed in the Okinawa area. Broadband and short-period seismographs of the 2004 Sumatra earthquake. Upper part shows the instrumentally corrected broadband seismograph at ZMM. Zero time denotes the occurrence time of the earthquake. The black and white triangles denote the estimated arrival time of the Rayleigh and Love waves, respectively. The velocity of the Rayleigh and Love waves is assumed to be $4.0 \mathrm{~km} / \mathrm{s}$ and $3.4 \mathrm{~km} / \mathrm{s}$, respectively. The thick vertical bar shows the scale of the broadband seismograph. Lower part shows the $2-4 \mathrm{~Hz}$ bandpass-filtered short-period seismograph of the $\mathrm{N}-\mathrm{S}$ component. The triggered LFEs were recorded at several stations. The waveforms are plotted from southwestern stations to northeastern stations along the trench

PGV in the vertical and transverse components of the surface waves with no filter for all events. The maximum amplitude of the LFEs was selected by combining the $2-4 \mathrm{~Hz}$ bandpass-filtered horizontal component waveforms. Next, the direction of arrival of the seismic wave to IGK and ZMM and the PGV were plotted.

\section{Results}

\section{Waveforms of the triggered LFEs}

In the Yaeyama and Okinawa areas, the LFEs were triggered during the passage of the surface wave of one teleseismic earthquake. Among 45 teleseismic earthquakes, LFEs were detected in five events.

In the Sumatra earthquake (Mw 9.1) of December 26, 2004, the LFEs were observed in the Yaeyama area when the surface waves passed at 1300-1700s (Fig. 2). The LFEs first arrived at the HATERS station, and then, they were delayed at stations east and west of the HATERS station. The LFE activity started when the maximum amplitude of the Love wave arrived rather than that of the Rayleigh wave (Fig. 2). In this earthquake, LFEs were observed even in the vicinity of Okinawa Island when the surface waves passed at 1500-1800s (Fig. 3). The LFEs arrived the earliest at ZMM or TAMAG2, and later at KUMEJ2 or KUNIGA stations. At 1500-1800s, two predominant phases were observed at various stations. At TAMAG2 and ZMM, weak but possible LFEs were detected at 1600-1700s. These phases were not observed at the other stations. The arrival time of these LFEs corresponded to those of the maximum amplitude of Love waves.

The LFEs were also observed in the waveforms of the Nias earthquake on March 28, 2005 (Mw8.6). However, the amplitudes of the LFE were the smallest among the five events in which LFEs were observed. The LFEs were observed at stations to the northeast of the HATERS station when the maximum amplitude of the Rayleigh wave arrived in the Yaeyama area (1100 s after the earthquake) (Additional file 4: Figure S2a). The LFEs were also observed in the Okinawa area during the passage of the surface waves (at approximately 1700s) (Additional file 5 : Figure S3a). The LFEs rapidly reached TAMAG2 and ZMM in the Okinawa area. The arrival time was closer to the passage time of the maximum amplitude of the Love wave (1600 s) than that of the Rayleigh wave (1200 s).

In the Wenchuan earthquake of 2008 (Mw7.9), LFEs were observed in the Yaeyama area when the surface waves passed at 700-900 s (Additional file 4: Figure S2b). The arrival of the LFEs was the fastest at the HATERS station. The LFEs were observed around the arrival of the maximum amplitude of the Love waves in the Yaeyama area. Similar LFEs were observed in Okinawa at 900$1000 \mathrm{~s}$ (Additional file 5: Figure S3b). The LFEs were first observed at ZMM and TAMAG2 at $950 \mathrm{~s}$, which was the arrival time of the maximum amplitude of the Rayleigh wave in Okinawa.

In the Sumatra earthquake of 2012 (Mw8.6), LFEs were observed in the Yaeyama area at 1500-2000s (Additional file 4: Figure S2c). The LFEs were first observed at the HATERS station and then at YONAGU. The LFEs intermittently continued after the passage of the maximum amplitude of the surface wave (Rayleigh waves and Love waves). Even in Okinawa, significant arrivals of LFEs were observed at 1300, 1600, and 1800s (Additional file 5: Figure S3c). The LFEs were observed around the arrival time of the maximum peak of the surface wave.

In the Gorkha earthquake in Nepal on April 25, 2015 (Mw7.8), the LFEs were observed in the Yaeyama area when the surface wave passed at 1200-1400 s (Additional 
file 4: Figure S2d). In the waveform, the arrival of LFE at $1200 \mathrm{~s}$ corresponded to the maximum amplitude of the Love wave, and the arrival of LFE at $1400 \mathrm{~s}$ corresponded to the maximum amplitude of the Rayleigh wave. After the passage of the surface wave (1900s or more), a plurality of LFEs were recorded at KUROSH, IGK, ISHIG2, and ISHIGH (Additional file 4: Figure S2d). The LFEs were observed around the maximum amplitude of the Love wave (1400-1600 s) even in the Okinawa area (Additional file 5: Figure S3d). The LFEs reached the TAMAG3 station the fastest. They were observed in the entire Okinawa area even after the surface wave passed at 1900s. The LFEs were observed at ZMM, TAMAG2, KUNIGA, and NAGOT at $2150 \mathrm{~s}$.

\section{Hypocenter distribution}

Seven LFEs were identified in the Yaeyama area (Fig. 4a, Additional file 2: Table S2). The hypocenters of LFEs generated during the passage of the surface waves were distributed around $24.0^{\circ} \mathrm{N}$ and $123.6^{\circ} \mathrm{E}$. The hypocenters of LFEs, which occurred immediately after the passage of the surface waves, were scattered around $24.0^{\circ} \mathrm{N}$ and $123.6^{\circ} \mathrm{E}$. The error in the determination of the hypocenter of LFEs in the 2004 event is shown by the contour lines in Fig. 4a. As the depth determination was not accurate, the determination error at the depth of $0 \mathrm{~km}$ was plotted. The contour line extended in the $\mathrm{N}-\mathrm{S}$ direction and had a large error in the direction perpendicular to the trench axis.

Seven LFEs were identified in the Okinawa area (Fig. 4b, Additional file 2: TableS2). Most of the LFEs were distributed around $25.8^{\circ} \mathrm{N}$ and $127.7^{\circ} \mathrm{E}$. The error of the hypocenter determination is shown by the contour lines in Fig. 4b. The contours extended obliquely to the trench axis, away from the seismic network near Okinawa Island. There was a large error in the direction away from the island. In the Okinawa area, the LFEs tended to occur separately, except for during the 2015 event. The hypocenters of the LFEs, which occurred immediately after the passage of the surface waves, were also distributed to the south of Okinawa Island. The difference in the distribution of the LFEs during and after the surface wave passage was not significant.

The LFEs were triggered at both stations for both components when the PGV was over $0.1 \mathrm{~cm} / \mathrm{s}$. The maximum amplitude at $2-4 \mathrm{~Hz}$ of the LFEs was 200 $500 \mathrm{~nm} / \mathrm{s}$ (Additional file 1: Table S1). The arrival direction of the surface waves in the events that triggered the LFEs was biased to $240-300^{\circ}$. Events with an arrival direction of $50^{\circ}$ did not trigger the LFEs, even though
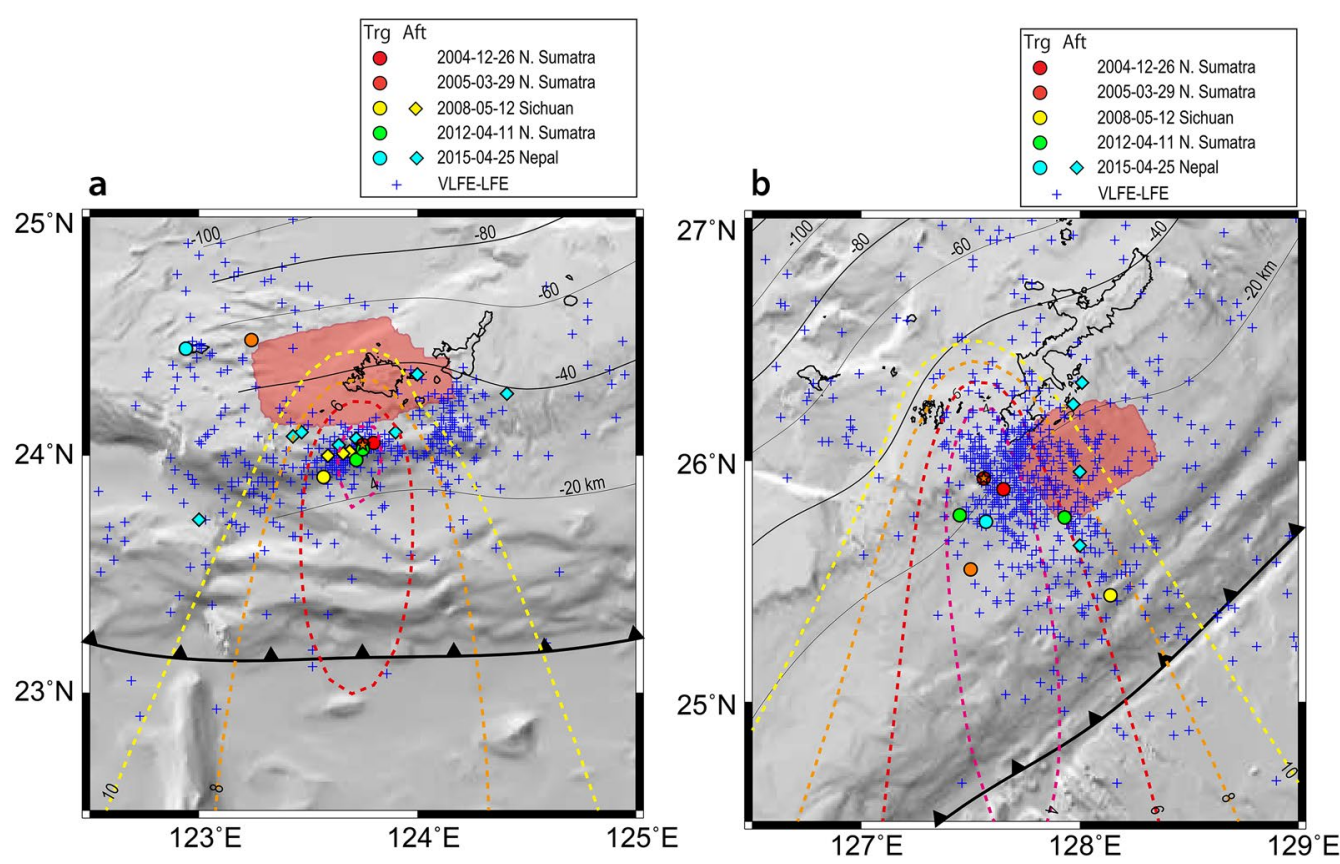

Fig. 4 Epicentral distribution of the LFEs. a Epicentral distribution of the LFEs in the Yaeyama area. Circles show the epicenter of the triggered LFEs during the passage of the surface waves. Diamonds denote the epicenters of LFEs after the passage of the surface waves. Colors of the circles and diamonds are different for each teleseismic event. The crosses show the epicenters of VLFE-LFEs (Nakamura 2017). The red hatch shows the slow slip event (SSE) area where the number of SSEs was over 5 (Nishimura 2014). The dotted contours show the RMS errors of the LFEs (denoted by stars) accompanying the surface wave of the 2004 Sumatra earthquake. The black-colored contour shows the depth of the plate interface (Hayer et al. 2012). $\mathbf{b}$ The same as a but for the Okinawa area 

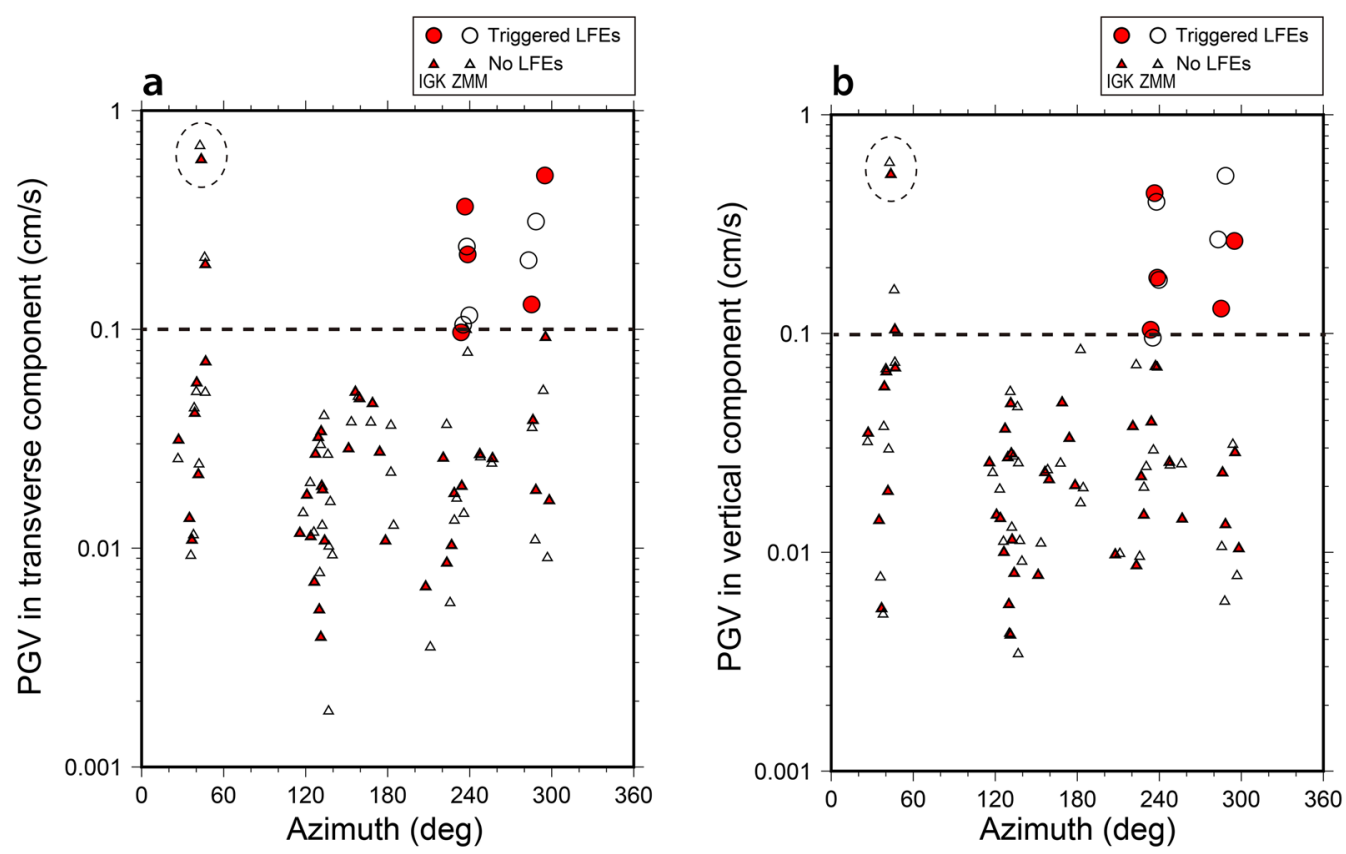

Fig. 5 PGV as a function of azimuth at IGK and ZMM. a PGV in transverse component as a function of incident azimuth to the stations. Circles show the data points for triggered LFEs. Triangles show the events where the triggered LFEs were not observed. Solid and open marks show the data points at IGK and ZMM, respectively. Ellipses show the data for the 2011 Tohoku-Oki earthquake. b The same as a but for the vertical component

the vertical and transverse PGV was greater than $0.1 \mathrm{~cm} / \mathrm{s}$ (Fig. 5).

\section{Discussion}

\section{Distribution of triggered LFEs and VLFE-LFEs}

The locations of both the triggered LFEs and VLFELFEs were close. The triggered LFEs occurred at $24.0^{\circ} \mathrm{N}$ and $123.6^{\circ} \mathrm{E}$ in the Yaeyama area and $25.8^{\circ} \mathrm{N}$ and $127.7^{\circ} \mathrm{E}$ in the Okinawa area (Fig. 4), very close to those of the VLFE-LFEs, which were determined by using the S-wave arrival time (Nakamura 2017) (Fig. 4). The VLFE-LFEs were distributed at $24.0^{\circ} \mathrm{N}$ and $123.6-124.1^{\circ} \mathrm{E}$ in the Yaeyama area (Nakamura 2017) (Fig. 4a), and at $25.8^{\circ} \mathrm{N}$ and $127.7^{\circ} \mathrm{E}$ in the Okinawa area, respectively (Nakamura 2017) (Fig. 4b). The locations of the triggered LFEs were up-dip of the SSEs in the Yaeyama area, and these were on the southwest side of the SSEs along the trench in the Okinawa area (Fig. 4). This is consistent with the distribution of the VLFE-LFEs.

The distribution of the triggered LFEs did not exactly match that of the VLFE-LFEs in the Yaeyama area. The clusters of the VLFE-LFEs were distributed at $123.6^{\circ} \mathrm{E}$ and $124.1^{\circ} \mathrm{E}$ in the Yaeyama area (Fig. 4a). The epicenters of the triggered LFEs corresponded to the cluster at $123.6^{\circ} \mathrm{E}$, while these were rare in the cluster at $124.1^{\circ} \mathrm{E}$. Because the seismic stations are distributed along the trench, the accuracy of the epicenter determination for the E-W direction is higher and these clusters can be divided (Nakamura 2017) (Fig. 4a). Therefore, the triggered LFEs would not have occurred in the cluster at $124.1^{\circ} \mathrm{E}$, and each cluster of the VLFE-LFEs in the Yaeyama area showed different sensitivity to induce LFEs. The VLFE-LFE activity was higher near the cluster at $123.6^{\circ} \mathrm{E}$ (Nakamura 2017), which suggests that the sensitivity of inducing LFEs was higher near $123.6^{\circ} \mathrm{E}$.

Similarly, although the clusters of VLFEs-LFEs in the Okinawa area were distributed not only at $25.8^{\circ} \mathrm{N}$ and $127.7^{\circ} \mathrm{E}$, but also to the southeast and east of Okinawa Island (Nakamura 2017), the induced LFEs occurred only at $25.8^{\circ} \mathrm{N}$ and $127.7^{\circ} \mathrm{E}$. High VLFEs-LFEs activity in Okinawa was distributed in $25.8^{\circ} \mathrm{N}$ and $127.7^{\circ} \mathrm{E}$ clusters. As in the Yaeyama area, this suggests that the sensitivity for inducing LFEs was higher near $25.8^{\circ} \mathrm{N}$ and $127.7^{\circ} \mathrm{E}$.

These results are consistent with those obtained in another subduction zone. The positional relationship between triggered and ambient tremors in subduction zones can be divided into two types. In the first type, the triggered tremor occurs in the region of ambient tremors such as in Taiwan and Aleutian Islands (Peterson et al. 2011; Chao et al. 2013). In the second type, the triggered tremor occurs on the up-dip side of the region of ambient tremors such as in Cascadia and west Shikoku (Kao and Shan 2004; Miyazawa et al. 2008; Kao et al. 2010; Obara et al. 2010; Chao et al. 2013; Chao and Obara 2016). In 
the case of the Ryukyu Trench, the accuracy of determining the position in the direction parallel to the trench is high, but the accuracy of determining the component perpendicular to the trench is low. Therefore, it is difficult to rule out that the triggered LFEs occurred on the up-dip side of the region of ambient tremors. In Kyushu, at the northern end of the Ryukyu Trench, triggered tremors occurred near the areas where shallow VLFEs and tremors occurred (Obara and Ito 2005; Yamashita et al. 2015; Chao and Obara 2016). This is consistent with the positional relationship between VLFEs-LFEs and triggered LFEs occurring in the Okinawa area and Yaeyama area. Unlike the Kyushu region, deep tremors or LFEs have not been identified in the Okinawa and Yaeyama areas. This indicates that triggered tremors could be common in or around the shallow VLFE and tremor area along the Ryukyu Trench.

\section{Threshold for triggered LFEs}

The threshold of the PGV, when the LFEs were triggered by Rayleigh and Love waves, was $0.1 \mathrm{~cm} / \mathrm{s}$ at IGK and ZMM. Here, we converted the PGV to dynamic stress $(\Delta \sigma)$. The phase velocity $(v)$ of the Rayleigh and Love waves was set to $4.0 \mathrm{~km} / \mathrm{s}$ and $3.4 \mathrm{~km} / \mathrm{s}$, respectively. Rigidity $(G)$ was set to $35 \mathrm{GPa}$. The dynamic stress can be expressed as follows (Chao and Obara 2016):

$$
\Delta \sigma=G \dot{u} / \nu .
$$

According to this equation, the PGV of $0.1 \mathrm{~cm} / \mathrm{s}$ corresponds to $8.7-10 \mathrm{kPa}$. This suggests that LFEs can be triggered by the dynamic stress in the order of $10 \mathrm{kPa}$ in Okinawa and Yaeyama. In a previous study, a tremor was detected in the southwestern part of the Ryukyu Arc when the dynamic stress was above $5 \mathrm{kPa}$ (Chao and Obara 2016), which is of the same order of magnitude as our result.

Here, we discuss the reasons the LFEs were not observed while the PGV was large enough to trigger the LFEs when the 2011 Tohoku-Oki earthquake occurred. The PGVs of the radial and transverse components of the 2011 Tohoku-Oki earthquake (Mw9.0) were $0.53 \mathrm{~cm} / \mathrm{s}$ and $0.60 \mathrm{~cm} / \mathrm{s}$, respectively, at IGK, and $0.60 \mathrm{~cm} / \mathrm{s}$ and $0.69 \mathrm{~cm} / \mathrm{s}$, respectively, at ZMM (Fig. 5a, b). These values were over the threshold $(0.10 \mathrm{~cm} / \mathrm{s})$ to trigger the LFEs. The amplitude of the horizontal waveforms at 2-4 Hz during the passage of the surface wave in the 2011 earthquake was on the order of $500 \mathrm{~nm} / \mathrm{s}$. The maximum amplitude of the induced LFE observed in other earthquakes was on the order of $200-500 \mathrm{~nm} / \mathrm{s}$ (Additional file 1: Table S1). It is possible that the coda part of the body wave was not sufficiently small when the surface wave passed because the epicentral distance was not far enough (approximately $2000 \mathrm{~km}$ ) and the triggered LFEs were obscured by the coda part of the body wave and could not be detected.

The arrival direction of the surface wave of the large PGV earthquakes was skewed southwestward except for the 2011 earthquake. Therefore, it was not possible to evaluate whether the threshold of the triggered LFE was azimuthally dependent or not.

\section{Conclusions}

We determined the distribution of triggered LFEs by dynamic stress changes in the surface waves in the central and southern areas of the Ryukyu Trench. The LFEs triggered by the surface waves of a large earthquake in the Ryukyu Islands were distributed to the south of the Okinawa and Yaeyama areas. These locations were overall consistent with the clusters of VLFEs-LFEs in this area. The triggered LFE activity was limited to the clusters in which the VLFEs-LFEs were originally active. This suggests that each cluster of the VLFEs-LFEs in the Yaeyama area had a different sensitivity to trigger LFEs.

The epicenters of the triggered LFEs in the Okinawa and Yaeyama areas are in or near the shallow VLFE area. This is consistent with the relationship between triggered tremors and shallow VLFEs observed in the Kyushu region at the northern end of the Ryukyu Trench. This indicates that triggered tremors could be common in or around the shallow VLFE and tremor area along the Ryukyu Trench.

The LFEs were triggered when the PGV of the surface waves was higher than $0.1 \mathrm{~cm} / \mathrm{s}$. This condition is similar to that in other areas where triggered tremors have been observed, which suggests that the LFEs observed in the Ryukyu Trench can be the result of the activation of ambient tremors due to increased stress.

\section{Abbreviations \\ JMA: Japan Meteorological Agency; LFE: Low-frequency earthquake; NIED: National Research Institute for Earth Science and Disaster Resilience; OBS: Ocean bottom seismometer; PGV: Peak ground velocity; RMS: Root-mean- square; SSE: Slow slip event; VLFE: Very low-frequency earthquake; VLFE- LFE: Low-frequency earthquakes accompanied with very low-frequency earthquakes.}

\section{Supplementary Information}

The online version contains supplementary material available at https://doi. org/10.1186/s40623-021-01442-z.

Additional file 1: Table S1. List of earthquakes used in this study and data on the earthquakes' peak ground velocity of the surface wave and amplitudes of LFEs.

Additional file 2: Table S2. List of the triggered LFEs.

Additional file 3: Figure S1. Waveforms of triggered LFEs observed in the Yaeyama area during the 2004 Sumatra earthquake. a $2-4 \mathrm{~Hz}$ bandpass-filtered short-period seismographs of the N-S component. $\mathbf{b}$ 
The same as a but $4-8 \mathrm{~Hz}$ bandpass-filtered. c The same as a but $8-16 \mathrm{~Hz}$ bandpass-filtered.

Additional file 4: Figure S2. Waveforms of the triggered LFEs observed in the Yaeyama area. a Broadband and short-period seismographs of the 2005 Nias earthquake. Upper part shows the instrumentally corrected broadband seismograph at IGK. Zero time denotes the occurrence time of the earthquake. The black and white triangles denote the estimated arrival time of the Rayleigh and Love waves, respectively. The velocity of the Rayleigh and Love waves is assumed to be $4.0 \mathrm{~km} / \mathrm{s}$ and $3.4 \mathrm{~km} / \mathrm{s}$, respectively. The thick vertical bar shows the scale of the broadband seismograph. Lower part shows the $2-4 \mathrm{~Hz}$ bandpass-filtered short-period seismograph of the $\mathrm{N}-\mathrm{S}$ component. The triggered LFEs were recorded at several stations. The waveforms are plotted from western stations to eastern stations along the trench. $\mathbf{b}$ The same as $\mathbf{a}$ but for the 2008 Wenchuan earthquake. $\mathbf{c}$ The same as a but for the 2012 Sumatra earthquake. $\mathbf{d}$ The same as a but for the $2015 \mathrm{Nepal}$ earthquake.

Additional file 5: Figure S3. Waveforms of the triggered LFEs observed in the Okinawa area. a Broadband and short-period seismographs of the 2005 Nias earthquake. Upper part shows the instrumentally corrected broadband seismograph at ZMM. Zero time denotes the occurrence time of the earthquake. The black and white triangles denote the estimated arrival time of the Rayleigh and Love waves, respectively. The velocity of the Rayleigh and Love waves is assumed to be $4.0 \mathrm{~km} / \mathrm{s}$ and $3.4 \mathrm{~km} / \mathrm{s}$, respectively. The thick vertical bar shows the scale of the broadband seismograph. Lower part shows the $2-4 \mathrm{~Hz}$ bandpass-filtered short-period seismograph of the $\mathrm{N}-\mathrm{S}$ component. The triggered LFEs were recorded at several stations. The waveforms are plotted from southwestern stations to northeastern stations along the trench. a The same as a but for the 2008 Wenchuan earthquake. a The same as a but for the 2012 Sumatra earthquake. $\mathbf{d}$ The same as a but for the 2015 Gorkha earthquake.

\section{Acknowledgements}

We thank the JMA and NIED for providing the waveform data. We used GMT (Wessel and Smith, 1998) to create the figures. We thank the two anonymous reviewers for providing constructive comments that helped to improve this manuscript.

\section{Authors' contributions}

AK carried out the analyses and wrote the manuscript. NM contributed to the interpretations and presentation of the manuscript. All authors read and approved the final manuscript.

\section{Funding}

This research was supported by JSPS KAKENHI Grant Number JP16H06473 for a Scientific Research on Innovative Areas program titled "Science of Slow Earthquakes"; funding was also provided by the Tokyo Marine Kagaki Memorial Foundation.

\section{Availability of data and materials}

The datasets used in this study are available from AK and MN upon reasonable request.

\section{Declarations}

Ethics approval and consent to participate

Not applicable.

\section{Consent for publication}

Not applicable.

\section{Competing interests}

The authors declare that they have no competing interests.

Received: 4 March 2021 Accepted: 18 May 2021

Published online: 31 May 2021

\section{References}

Arai R, Takahashi T, Kodaira S, Kaiho Y, Nakanishi A, Fujie G, Nakamura Y, Yamamoto Y, Ishihara Y, Miura S, Kaneda Y (2016) Structure of the tsunamigenic plate boundary and low-frequency earthquakes in the southern Ryukyu Trench. Nat Commun 7:12255. https://doi.org/10.1038/ncomms12255

Chao K, Obara K (2016) Triggered tectonic tremor in various types of fault systems of Japan following the 2012 Mw8.6 Sumatra earthquake. J Geophys Res 121:170-187. https://doi.org/10.1002/2015JB012566

Chao K, Peng Z, Wu C, Tang CC, Lin CH (2012b) Remote triggering of nonvolcanic tremor around Taiwan. Geophys J Int 188:301-324. https://doi. org/10.1111/j.1365-246X.2011.05261.x

Chao K, Peng Z, Fabian A, Ojha L (2012a) Comparisons of triggered tremor in California. Bull Seismol Soc Am 102(2):900-908. https://doi.org/10.1785/ 0120110151

Chao K, Peng Z, Gonzalez-Huizar H, Aiken C, Enescu B, Kao H, Velasco AA, Obara K, Matsuzawa T (2013) A global search for triggered tremor following the 2011 Mw 9.0 Tohoku Earthquake. Bull Seism Soc Am 103:15511571. https://doi.org/10.1785/0120120171

Fry B, Chao K, Bannister S, Peng Z (2011) Deep tremor beneath the Hikurangi margin in New Zealand triggered by the $2010 \mathrm{Mw} 8.8$ Chile earthquake. Geophys Res Lett 38:LI5306. https://doi.org/10.1029/2011 GL048319

Gomberg J (2010) Lessons from (triggered) tremor. J Geophys Res 115:B10302. https://doi.org/10.1029/2009JB007011

Gomberg J, Rubinstein JL, Peng Z (2008) Widespread triggering of nonvolcanic tremor in California. Science 319:173. https://doi.org/10.1126/science. 1149164

Hayers GP, Wald DJ, Johnson RL (2012) Slab1.0: a three-dimensional model of global subduction zone geometries. J Geophys Res 117:B01303. https:// doi.org/10.1029/2011JB008524

Ide S (2012) Variety and spatial heterogeneity of tectonic tremor worldwide. J Geophys Res 117:B03302. https://doi.org/10.1029/2011JB008840

Ito Y, Hino R, Suzuki S, Kaneda Y (2015) Episodic tremor and slip near the Japan Trench prior to the 2011 Tohoku-Oki earthquake. Geophys Res Lett 42:1725-1731. https://doi.org/10.1002/2014GL062986

Kao H, Shan SJ (2004) The source-scanning algorithm: mapping the distribution of seismic sources in time and space. Geophys J Int 157(2):589-594. https://doi.org/10.1111/j.1365-246X.2004.02276.x

Kao H, Wang K, Dragert H, Kao JY, Rogers G (2010) Estimating seismic moment magnitude (Mw) of tremor bursts in northern Cascadia: implications for the "seismic efficiency" of episodic tremor and slip. Geophys Res Lett 37(19):L19306. https://doi.org/10.1029/2010GL044927

Miyazawa M, Mori J (2006) Evidence suggesting fluid flow beneath Japan due to periodic seismic triggering from the 2004 Sumatra-Andaman earthquake. Geophys Res Lett 33:L05303. https://doi.org/10.1029/2005G L025087

Miyazawa M, Brodsky E, Mori J (2008) Learning from dynamic triggering of low-frequency tremor in subduction zones. Earth Planets Space 60:e17e20. https://doi.org/10.1186/BF03352858

Nadeau R, Dolenc D (2005) Nonvolcanic tremors deep beneath the San Andreas fault. Science 307(5708):389. https://doi.org/10.1126/science. 1107142

Nakamura M (2017) Distribution of low-frequency earthquakes accompanying the very low frequency earthquakes along the Ryukyu Trench. Earth Planets Space 69:49. https://doi.org/10.1186/s40623-017-0632-4

Nishimura T (2014) Short-term slow slip events along the Ryukyu Trench, southwestern Japan, observed by continuous GNSS. Prog Earth Planet Sci 1:22. https://doi.org/10.1186/s40645-014-0022-5

Obara K (2002) Nonvolcanic deep tremor associated with subduction in southwest Japan. Science 296:1679-1681. https://doi.org/10.1126/scien ce. 1070378

Obara K, Ito Y (2005) Very low frequency earthquakes excited by the 2004 off the Kii peninsula earthquakes - a dynamic deformation process in the large accretionary prism. Earth Planets Space 57(4):321-326. https://doi. org/10.1186/BF03352570

Obara K, Kato A (2016) Connecting slow earthquakes to huge earthquakes. Science 353:253-257. https://doi.org/10.1126/science.aaf1512

Obara K, Kodaira S (2009) Low-frequency tremors associated with reverse faults in a shallow accretionary prism. Earth Planet Sci Lett 287:168-174. https://doi.org/10.1016/j.epsl.2009.08.005 
Obara K, Tanaka S, Maeda T, Matsuzawa T (2010) Depth-dependent activity of non-volcanic tremor in southwest Japan. Geophys Res Lett 37(13):L13306 https://doi.org/10.1029/2010GL043679

Payero J, Kostoglodov V, Shapiro N, Mikumo T, Iglesias A, Pérez-Campos X, Clayton R (2008) Nonvolcanic tremor observed in the Mexican subduction zone. Geophys Res Lett 35(7):L07305. https://doi.org/10.1029/2007G L032877

Peng Z, Vidale JE, Creager KC, Rubinstein JL, Gomberg J, Bodin P (2008) Strong tremor near Parkfield, CA, excited by the 2002 Denali Fault earthquake. Geophys Res Lett 35:L23305. https://doi.org/10.1029/2008GL036080

Peterson C, McNutt S, Christensen D (2011) Nonvolcanic tremor in the Aleutian Arc. Bull Seismol Soc Am 101(6):3081-3087. https://doi.org/10.1785/ 0120100241

Rogers G, Dragert H (2003) Episodic tremor and slip on the Cascadia subduction zone: the chatter of silent slip. Science 300(5627):1942-1943. https:// doi.org/10.1126/science.1084783

Rubinstein JL, Vidale JE, Gomberg J, Bodin P, Creager KC, Malone SD (2007) Non-volcanic tremor driven by large transient shear stresses. Nature 448:579-582. https://doi.org/10.1038/nature06017

Sun WF, Peng Z, Lin CH, Chao K (2015) Detecting deep tectonic tremor in Taiwan with a dense array. Bull Seismol Soc Am 105(3):1349-1358. https:// doi.org/10.1785/0120140258

Tanaka S, Matsuzawa T, Asano Y (2019) Shallow low-frequency tremor in the northern Japan Trench subduction zone. Geophys Res Lett 46:5217-5224. https://doi.org/10.1029/2019GL082817
Ueno H, Hatakeyama S, Aketagawa T, Funasaki J, Hamada N (2002) Improvement of hypocenter determination procedures in the Japan meteorological agency (in Japanese). Quart J Seis 65:123-134

Walter JI, Schwartz SY, Protti JM, Gonzalez V (2011) Persistent tremor within the northern Costa Rica seismogenic zone. Geophys Res Lett 38:L01307. https://doi.org/10.1029/2010GL045586

Wessel P, Smith W (1998) New, improved version of Generic Mapping Tools released. Eos Trans AGU 79(47):579. https://doi.org/10.1029/98EO00426 Yamashita Y, Yakiwara H, Asano Y, Shimizu H, Uchida K, Hirano S, Umakoshi K, Miyamachi H, Nakamoto M, Fukui M, Kamizono M, Kanehara H, Yamada T, Shinohara M, Obara K (2015) Migrating tremor off southern Kyushu as evidence for slow slip of a shallow subduction interface. Science 348(6235):676-679. https://doi.org/10.1126/science.aaa4242

\section{Publisher's Note}

Springer Nature remains neutral with regard to jurisdictional claims in published maps and institutional affiliations.

\section{Submit your manuscript to a SpringerOpen ${ }^{\odot}$ journal and benefit from:}

- Convenient online submission

- Rigorous peer review

- Open access: articles freely available online

- High visibility within the field

- Retaining the copyright to your article

Submit your next manuscript at $\boldsymbol{\nabla}$ springeropen.com 